\title{
ID-THINK: facilitador da visualização dos conhecimentos da empresa
}

\section{ID-THINK: facilitator of visualization of the company's knowledge.}

Demarchi, Phd Ana Paula Perfetto

Universidade Estadual de Londrina perfeto@sercomtel.com.br

\author{
Fornasier, Phd Cleuza Bittencourt Ribas \\ Universidade Estadual de Londrina \\ cleuzafornasier@gmail.com \\ Ortuño, Phd. Bernabé Hernandis \\ Universidad Politecnica de Valencia \\ bhernandis@degi.upv.es \\ Marquina, Msc Elingth Simoné Rosales \\ Pontificia Universidad Javeriana de Cali \\ elingthsimone@gmail.com
}

\begin{abstract}
Resumo: Este artigo relata o projeto desenvolvido na Universidade Politécnica de Valencia em conjunto com a Universidade Estadual de Londrina, o qual resultou em um produto que pretende facilitar o desenvolvimento da gestão do conhecimento e sua visibilidade a partir dos objetivos a serem perseguidos, por meio da transmissão de informações e conhecimentos e da transformação destas em ações e novos conhecimentos. Para tanto, utilizou-se dos conceitos do design thinking e das habilidades inerentes aos design thinkers, desenvolveu-se uma interface que auxilia a integração dos conhecimentos de todos os envolvidos na gestão da organização.
\end{abstract}

Palavras-chave: Modelo sistêmico, Gestão do conhecimento, Design Thinking.

Abstract: This article reports the project developed at the Polytechnic University of Valencia (UPV) in conjunction with the State University of Londrina (UEL), which resulted in a product that aims to facilitate the development of knowledge management and its visibility from the objectives to be pursued through the information and knowledge's transmission and the transformation of these in actions and new knowledge. To this end, we 
used the concepts of the design thinking and the skills inherent to design thinkers, whereas the procedures adopted, the creative process and the perceptions and from these, to develop an interface that assists the integration of knowledge of everyone involved in the Organization's management.

Key words: Systemic Model, Knowledge Management, Design Thinking.

\section{INTRODUÇÃO}

Esta pesquisa promove mudanças organizacionais pela inserção da Gestão do Conhecimento, que preserva as características da organização, a lógica de produção, o respeito à diversidade cultural, e também coopera para que haja a inserção do produto na lógica empresarial por meio do entendimento mercadológico, gerenciadas pelos design thinkers.

O design thinker traduz observações em insigths e insights em produtos e serviços. Não só os designers podem ser design thinkers, mas aqueles que têm as mesmas experiências e habilidades integrativas e holísticas do design thinker, (nas organizações, nas sociedades e na vida). Sabe-se que o acúmulo de experiências durante a vida possibilita aguçar a sensibilidade e habilidades.

O design thinker extrai conhecimentos (tácito, cultural, objetivo e explícito) das organizações (Demarchi, Fornasier, Martins, 2013), codifica-os e gera conhecimento organizacional para produzir o conhecimento objetivo, agregando valor aos produtos e contribuindo para torná-los mais competitivos. Porém, os novos conhecimentos são criados a partir do conhecimento subjetivo que avalia as informações e conhecimentos a que os sujeitos são expostos. Por isto, que a informação só se torna conhecimento, pelo pensamento reflexivo, que é a forma analítica de extrair sentido das informações.

Este artigo descreve um produto desenvolvido por este grupo de pesquisadores, que permite visualizar o plano de empresa sobre um suporte material, a partir da representação gráfica dos vários conhecimentos atribuídos a organização.

O produto facilita a visualização do seguimento contínuo dos objetivos da empresa, auxilia a visualização do problema de maneira global, por meio de um processo gráfico que garante retroalimentações tanto nas estruturas disponíveis, quanto nos recursos humanos e materiais, assim como facilita a visualização das ações e fluxos de informações correspondentes as decisões necessárias para a produção de produtos e serviços. O produto demonstra também quais são as habilidades e as atitudes de design thinker que o gestor deve ter em cada etapa, o que facilita a aplicação da gestão do conhecimento na organização.

O produto utiliza os conceitos do Modelo Sistêmico de Hernandis (2003) agregado de conceitos proposto na Gestão Estratégica Integradora de Design Aprimorado (GelDa) de Demarchi, Fornasier e Martins (2013), sendo estes modelos baseados na gestão do conhecimento. 


\section{GESTÃO DO CONHECIMENTO}

O modelo GelDa (Demarchi, Fornasier e Martins, 2013), adota a segunda fase da gestão do conhecimento considerando o modelo de Mark W. McElroy lapud Firestone e McElroy, 2003), construído pelo trabalho conjunto com o Knowledge Management Consortium International ( $K M \mathrm{Cl}$ ) que vê a primeira fase como centrada na produção (oferta) do conhecimento, que presumia que os conhecimentos valiosos já existem. Esta primeira fase, para os autores, é centrada no trabalho de Nonaka e Takeuchi (1997), que considerava o conhecimento como externalizado e a disposição para ser processado pela informação.

No entanto, Firestone e McElroy (2003) consideram a segunda fase da gestão do conhecimento, como surgida na metade da década de 90 , focada na oferta do conhecimento, no compartilhamento e também na demanda do conhecimento, ou seja, na produção do conhecimento em resposta à demanda induzida por um problema. Este foco combina a produção com a integração do conhecimento, sendo esta a característica básica da definição da Segunda Geração da Gestão do Conhecimento (SGGC) ou a Nova Gestão do Conhecimento (NGC).

De acordo com os autores um importante aspecto da NGC é o reconhecimento de que organizações são permeadas de um fenômeno do sistema adaptativo complexo. Nesse contexto, a gestão do conhecimento baseia-se na utilização deste sistema para a adaptação organizacional, que possibilita e reforça a autoorganização e processa o conhecimento para atingir uma acelerada inovação sustentável. Lembrando que o modelo de McElroy (2003, p. 5), apresenta o conhecimento como algo produzido por "sistemas sociais humanos, que fazemos isso por meio de processos individuais e por compartilhamento que regularmente acontece entre os seres humanos".

O produto, a que se refere este artigo, adota a NGC, e consequentemente visa a interdependência da produção e da integração do conhecimento, apesar de neste momento, o produto apresenta somente a produção do conhecimento, mas será ampliado.

O Modelo Sistêmico (Hernandis, 2003) é um aparato que gestiona dados, informação e conhecimento. Convêm reforçar que basicamente os dados são provenientes quando ocorre a definição dos componentes do sistema exterior por meio das variáveis de entrada. Neste ponto é oportuno destacar a importância da abordagem sistêmica para potencializar a compreensão integral do processo de gestão do conhecimento. Como assinala Cross (2011), a perspectiva é contextual e, portanto, não só a análise da estrutura como também a qualidade do sistema estudado e suas interações, aspectos que são essenciais para este projeto. Portanto, a gestão de dados, informação e conhecimentos articulam-se com conceitos fundamentais associados a noção de análise sistêmica como a proposta por Joel de Rosnay (1979), que "[...]consiste em definir os limites do sistema a modelar; em identificar os elementos importantes e os tipos de interações entre estes elementos; depois, em determinar os enlaces que os integraram em um todo organizado" (p.85).

A contribuição proposta do Modelo Sistêmico será justamente no processo de extração do conhecimento, assim o modelo trabalha com dados, informações e conhecimentos, considerando os conhecimentos explicitados (objetivo e 
explícito) e conhecimentos não explicitáveis (conhecimento tácito e cultural) estudados por Demarchi, Fornasier e Martins (2010).

O conhecimento objetivo é o conteúdo lógico de nossas teorias, conjecturas e suposições explicitados em procedimentos aparentes nos produtos, tecnologia, arte, arquitetura, linguagem escrita e falada, mitos, rituais e histórias, enfim são os fenômenos que alguém vê, ouve e sente, quando depara-se com um novo grupo, ou com uma cultura não familiar. O conhecimento explícito está na linguagem formal, em afirmações gramaticais, expressões matemáticas, especificações, e manuais sendo transmitido, formal e facilmente entre os sujeitos.

O conhecimento tácito é compartilhado a partir de exemplos ou demonstrações, quando se trata da experiência "do fazer" é difícil de ser verbalizado ou explicitado, pois é o conhecimento pessoal incorporado à experiência individual e envolve fatores intangíveis como as crenças pessoais, perspectivas e sistemas de valores. Muitas vezes pode ser somente compartilhado por meio de discurso como: analogias, metáforas e compartilhamento de histórias. Apesar de o conhecimento tácito ter característica pessoal, as organizações possuem conhecimento tácito em torno de práticas que a tornam diferentes entre si.

Conhecimento cultural está expresso nas crenças, normas e pressupostos usados para dar valor e importância a novos conhecimentos e informações, não é codificado, mas divulgado por vínculos e relacionamentos que ligam um grupo, e que por meio da linguagem constrói-se o sistema que articula com outros sujeitos. As crenças são sustentadas como verdades, porque são construídas por determinadas referências da realidade a partir de aceitações anteriores formuladas pelo grupo.

À medida que estes conhecimentos são explicitados, vão sendo anexados ao produto proposto a partir de dois tabuleiros, que facilitam a visualização da externalização do conhecimento. Demarchi, Fornasier e Martins (2010) a definem como a ação de extrair os conhecimentos explícitos e culturais do ambiente, que se articulam com as necessidades latentes do sujeito (conhecimento subjetivo), pois ao compartilhar um conhecimento, o sujeito adquire outro conhecimento, ou muda as crenças e valores enraizados.

A partir da relação dos cinco conhecimentos pode-se produzir um novo conhecimento. Observa-se que três dos conhecimentos apresentados anteriormente não podem ser explicitados. O conhecimento tácito e o conhecimento cultural podem ser compartilhados, mas não externalizados; e o conhecimento subjetivo não é nem explicitado, nem compartilhado, é somente alterado quando ocorrem as relações de sociabilidade, o que justifica a dificuldade em extrair os conhecimentos, e coloca em xeque o entendimento de Nonaka e Takeuchi (1997) de que o conhecimento está pronto para ser trabalhado.

Para poder utilizar os conhecimentos durante o processo de design, deve ocorrer o processo de aprendizagem. Aprende-se por meio de um processo que inclui o conhecimento investigado, associando-o ao saber como fazer algo, e ao saber que este algo é feito desta ou daquela maneira, ou seja, da teoria e da prática, numa ação sistêmica. Este ciclo ocorre durante a conversão do conhecimento, pois o designer precisa aprender para poder sintetizá-lo e convertê-lo em outra linguagem.

Para produzir um novo conhecimento é necessário fazer a sua extração e conversão pela interação dos cinco conhecimentos articulados em quatro possíveis modos de conversão que são a essência do Processo de Produção do Conhecimento. 
A Externalização é conseguida pelo compartilhamento de experiências. Esta fase é muito importante para o designer, e provavelmente a que ele tem maior dificuldade, pois necessita tirar das pessoas o que sabem e querem que seja importante para o trabalho, considerando que nem elas mesmas sabem que sabem, ou o que querem, "ajudar as pessoas a articularem as novas necessidades que eles podem nem saber que têm" (Brown, 2009, 40) é um desafio que pode ser solucionado utilizando as habilidades dos design thinkers. O designer é ajudado por algumas ferramentas, como ir ao campo observar o comportamento das pessoas enquanto elas agem, o que proporciona pistas valiosas sobre uma lista de necessidades insatisfeitas.

Na Explicitação o pesquisador normalmente incentiva a socialização a partir de metáfora e/ou analogia, importantes para a criação de uma rede conceitual, como também: contação de histórias (storytelling- metáforas para externalizar conceitos e transmitir ideias ou eventos); e o pensamento visual (visual thinking - para explicitar conceitos). Após, sintetiza as observações que serão agrupadas e a partir delas formularão outros conhecimentos, por meio da redução do conhecimento, a primeira do Processo de Produção do Conhecimento.

Na Experimentação compartilha-se o conhecimento explícito, por meio das habilidades criativas e experimentais. Desmembram-se as ideias surgidas e se operacionalizam as visões explicitadas conseguidas pelas pesquisas qualitativas, quantitativas, e na construção de protótipos. Eles são utilizados como modelo, como uma representação física ou matemática de um objeto, ou pode ser ainda "qualquer coisa tangível que nos deixe explorar uma ideia, avaliá-la e levá-la adiante" (Brown, 2009, p.92). Portanto, a experimentação é o processo de sistematização de conceitos em um sistema de conhecimento.

A Estratégia é o processo de redução progressiva para chegar a uma alternativa de aplicação estratégica formada pelo conhecimento explicitado. Está relacionada ao "aprender fazendo", já que "para que o conhecimento tácito torne-se explícito, é necessária a verbalização e diagramação do conhecimento sob a forma de documentos, manuais ou histórias orais"(Nonaka e Takeuchi, 1997, p.78)

O modelo proposto é um modelo de explicitação de conhecimentos adquiridos do sistema exterior e que entram no modelo por meio de variáveis de entrada. No entanto, essas variáveis também contêm conhecimentos não explicitados, sendo necessária a realização da extração do conhecimento em uma etapa anterior que se materializa no modelo proposto no primeiro tabuleiro que orienta o pesquisador a colocar em prática os conceitos de design thinking, assim como as habilidades inerentes ao design thinker, principalmente a habilidade de visual thinking.

\section{DESIGN THINKING}

O Design Thinking, apesar de ser considerado novo, ele sempre esteve presente, é uma nova maneira de pensar e utilizar o processo de design, mesmo que a nível inconsciente. Ilipinar et all (2008) dizem que o design thinking é um processo criativo baseado na construção de ideias, que elimina o medo de falhar por não haver julgamento, por isto encoraja a máxima absorção e participação dos indivíduos no processo de resolução de problemas. Roger Martin, citado pelos autores, vê o design thinking como fonte de vantagem competitiva e consideram-o como fator essencial para as organizações obterem inovação. 
Dyer, Gregersen e Christensen (2011) concordam que a inovação revolucionária (disruptiva) é desencadeada pela habilidade que os inovadores possuem de ligar ideias (pensamento associativo), no entanto, os inovadores não só pensam de maneira diferente, mas também agem de forma diferente. Alguns observam o mundo com uma intensidade maior que os indivíduos comuns, outros criam network formando um grupo colaborativo, enquanto outros se engajam em ações experimentais. Eles afirmam que a inovação e a criatividade não são só habilidades cognitivas, são uma questão de comportamento. A partir disto, os autores criaram um modelo que demonstra o DNA de pessoas inovadoras para gerar ideias inovadoras, demonstrado na figura 1 abaixo.

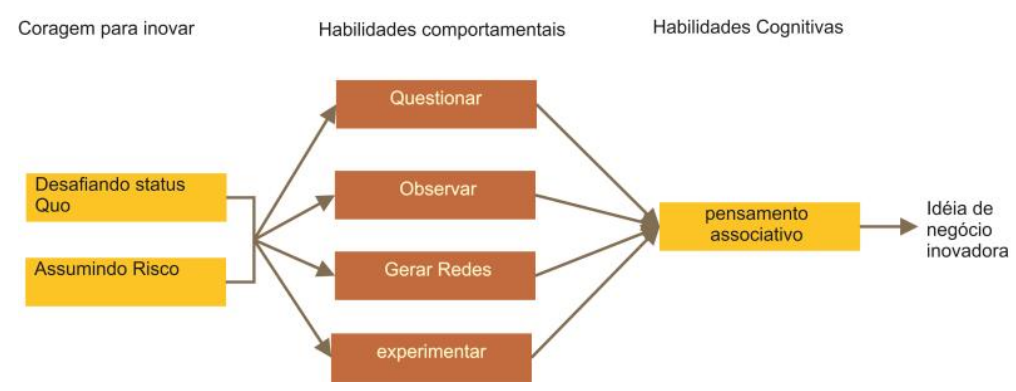

Fig1: Modelo de DNA de Inovadores

Fonte: Adaptado de Dyer, Gregersen e Christensen (2011, p.27)

Observou-se que as habilidades comportamentais, e cognitivas dos inovadores são as mesmas dos design thinkers. Para Brown (2009), o design thinking inicia com as habilidades que os designers aprenderam no decorrer do tempo; como a de alinhar as necessidades dos seres humanos com o recurso tecnológico disponível na organização, na intuição, na habilidade de reconhecer padrões, construir ideias que tenham significado tanto emocional quanto funcional, na habilidade de questionar o entorno e ser empático, e a habilidade de expressar de outra maneira que não em palavras ou símbolos, mas desenhando.

Ao que parece o processo de design é difícil de conduzir por processos mentais puramente internos, o designer precisa interagir com uma representação externa por isto que Cross (2011, p.12) diz: "O ato de desenhar parece clarear meus pensamentos", já que há um limite cognitivo para a quantidade de complexidade que pode ser manipulada no cérebro. Esboçar fornece um depósito temporário e externo para ideias tentadas, e essa externalização suporta o diálogo que o designer tem entre o problema e a solução, sendo a principal habilidade do designer.

O processo de desenho é tanto um processo de crítica, como meio de materialização, imaginação, ou descoberta de algo que não pode ser construído na sua mente, e também como um meio de comunicação com os outros. De acordo com Cross (2011) nesses casos, o design torna-se não somente um processo pessoal e cognitivo, mas um processo partilhado e social. Esse processo leva a outra habilidade, que, segundo Brown (2009), é a de trabalhar de forma interdisciplinar e de criar redes.

De acordo com Schon (apud Cross, 2011, p.23), o design procede como "uma conversação reflexiva da situação" um processo interativo baseado em apresentar um quadro do problema e explorar as implicações a partir de 'movimentos' que investigam 
as decorrentes possibilidades de solução. Esses movimentos envolvem todos da equipe interdisciplinar.

Portanto, o design thinker observa o ordinário e grava as suas observações e ideias visualmente; ele tem em si a habilidade de expressar suas ideias visualmente. A cultura do design thinking encoraja a criação do protótipo, que não deixa de ser uma maneira de pensar visualmente, pois o protótipo é uma maneira de validar ideias finais, sendo também parte do processo de criação. Brown (2009, p.231) relata que os protótipos precisam ser testáveis, mas não necessariamente físicos, podem ser "storyboards, cenários, filmes, e até um improviso teatral".

Praticantes do design thinking competentes sabem mais do que conseguem dizer, porque é um tipo de saber-na-prática, sendo que a maioria são conhecimentos tácitos. Brown (2009) identificou um processo cognitivo de reflexão-em-ação que é um quadro experimental no qual o design thinker encontra uma maneira de ver a problemática a partir da realização de protótipos, como a inteligência que guia o comportamento 'intuitivo' em contextos práticos que fazem pensar-e-agir.

As técnicas de design como: esboçar, construir protótipos, fazer maquetes, cenários, etc., habilitam o designer a fazer um "inquérito da futura situação de uso". Estas técnicas fazem parte do mundo da cognição, e fornecem ao designer um conjunto de "estratégias situadas". Gedenryd (apud Cross, 2011, p.27) argumenta que a visão cognitiva como puramente racional e uma atividade 'intra-mental' (unicamente dentro da mente) é errônea, mas a reconhece como uma atividade prática e interativa. $\mathrm{O}$ ato de design é uma atividade intensa de cognição, que possui a necessidade de manter períodos de atividade intensa de intuição, intercaladas com períodos de contemplação mais reflexiva, usualmente fora do ambiente normal de trabalho.

Para Lockwood (2009) os atributos do design thinking são: habilidade de criar o futuro em vez de reagir à condição presente; ser colaborativo; ser empático; ser um visual thinker; integrativo; criativo; e trabalhar com a diferenciação. Para ser designer e líder requer-se "habilidade de imaginar 'o que ainda não existe' para criar novo significado ou novas realidades, para encontrar direção, operar com intenção e propósito, e operar em um mundo praticamente mudando a complexidade e informação". O quadro abaixo gera a relação de semelhanças entre as habilidades e atributos do design thinker com o DNA de inovadores.

Tab. 1: Comparação entre as habilidades e atitudes do design thinker com o DNA do inovador

\begin{tabular}{|l|l|l|l|}
\hline $\begin{array}{l}\text { Habilidades e atitudes do } \\
\text { design Thinker }\end{array}$ & $\begin{array}{l}\text { Habilidades comportamentais } \\
\text { do inovador }\end{array}$ & $\begin{array}{l}\text { Habilidades Cognitivas } \\
\text { do inovador }\end{array}$ & \begin{tabular}{l} 
Coragem de inovar \\
\hline Observação empática \\
Questionarar
\end{tabular} \\
\hline $\begin{array}{l}\text { Colaborativa } \\
\text { Integrativo }\end{array}$ & Criar rede & & \\
\hline Gerar protótipos & Experimental & & \\
\hline $\begin{array}{l}\text { Criativo } \\
\text { Visual thinkers }\end{array}$ & Pensamento associativo & \\
\hline Trabalhar com a diferenciação & & & Desafiar o Status Quo \\
\hline $\begin{array}{l}\text { Visão de futuro } \\
\text { Assumir risco }\end{array}$ & & & Assumir risco \\
\hline
\end{tabular}


Chesbrough (2012) diz que a inovação não é invenção, mas é a invenção implantada e levada ao mercado. A inovação revolucionária (disruptiva) é aquela que altera as práticas sociais (modo de viver, aprender e trabalhar). Como visto acima na Tabela 1, as habilidades do design thinker auxiliam a implantação da inovação revolucionária (disruptiva), que é essencial para a sobrevivência das organizações.

O produto aqui demonstrado foi desenvolvido no intuito de potencializar o uso destas habilidades. O ID-Think define maneiras de processar conhecimentos não explicitáveis por meio da sua habilidade de visual thinking, representando a maneira de pensar dos designers, com objetivo de tornar visíveis os conhecimentos para transformá-los em produtos e processos de sucesso.

\section{METOdOLOGIA}

Tanto Hernadis (2003) quanto Demarchi, Fornasier, e Martins (2013) desenvolveram modelos conceituais baseados na gestão do conhecimento. A justaposição dos dois conceitos com a aplicação dos conceitos de design thinking possibilitou o desenvolvimento deste produto.

No primeiro momento foi necessário o aprendizado por parte do grupo de como funcionava os dois modelos e dos conceitos de design thinking. Depois foram realizadas sessões de contações de histórias por ambas as partes para que ocorressem os aprendizados dos novos conceitos, para depois por meio de brainstorming possibilitar a geração dos tabuleiros do jogo e do modo de utilização. Por último, realizaram-se os protótipos para que fossem aplicados em empresas pilotos e assim realizados os devidos ajustes. O trabalho caracterizou-se como um trabalho de cocriação, no qual toda a equipe participou das diferentes etapas de realização.

\section{IDTHINK: UM JOGO EMPRESARIAL}

ID-Think foi o nome dado ao produto que é caracterizado como um jogo empresarial, tendo como objetivo auxiliar o processo de criação e planejamento de empresas, assim como para a análise, descrição, e detecção de problemas, para posterior correção de desvios de gestão empresarial.

Durante a modelagem do produto devem participar diretores, gestores, design thinkers, e pessoas diretamente envolvidas com a área ou empresa em questão. 0 processo é de cocriação, o que significa que todos deverão determinar os problemas da empresa/área planificando e determinando ações corretivas futuras, para que a empresa se adapte ao entorno e evolua. Como todo processo deve haver um líder, alguém com habilidades propícias para ajudar a realizar a externalização dos conhecimentos e que dirija as ações de preenchimento do modelo.

O produto constitui-se de dois tabuleiros. O primeiro tabuleiro é o Sistema Exterior, o segundo tabuleiro é o Sistema de Empresa e abaixo do último existe uma faixa mais estreita, aonde serão colocados os objetivos já cumpridos, denominada de Faixa de Objetivos Cumpridos. Lembrando que o produto auxilia no processo de criação e planejamento de empresas a partir das definições dos objetivos em cada um dos níveis empresarial e a partir deles define-se quem realizará o que, de que maneira, com o que e quando será realizado e o mesmo processo ocorre para ser validado. 
Os dois tabuleiros possuem quadros específicos que facilitam a localização das ações a serem realizadas. A modelagem é induzida pela disposição destes quadros que serão preenchidos com os materiais incluídos na maleta do jogo, como post its, marcadores, e fichas específicas com imagens ou com conceitos escritos.

O tabuleiro completo deve ficar pendurado a partir dos dois orifícios superiores. Ele possui indicação numérica de um (1) a vinte e seis (26), que indicam a ordem correta de preenchimento, por mais que tenham dificuldade sugerimos que não pulem nenhuma das etapas, isto só dificultará o entendimento.

O sistema em estudo é a organização, mesmo que o estudo abranja apenas parte dela. O primeiro espaço a ser preenchido no tabuleiro é o nome e a atividade que a empresa realiza, passando depois para o sistema exterior. O sistema exterior é a realidade externa que rodeia a empresa, e por sua vez levanta um problema de design.

O Sistema Exterior é onde se copila toda a informação relativa ao entorno da empresa e se analisa mediante diversas ferramentas de transcendência da informação, gerando uma síntese mediante conceitos base, fotografias ou representações gráficas que constituem a informação fundamental da realidade da empresa (figura 2).

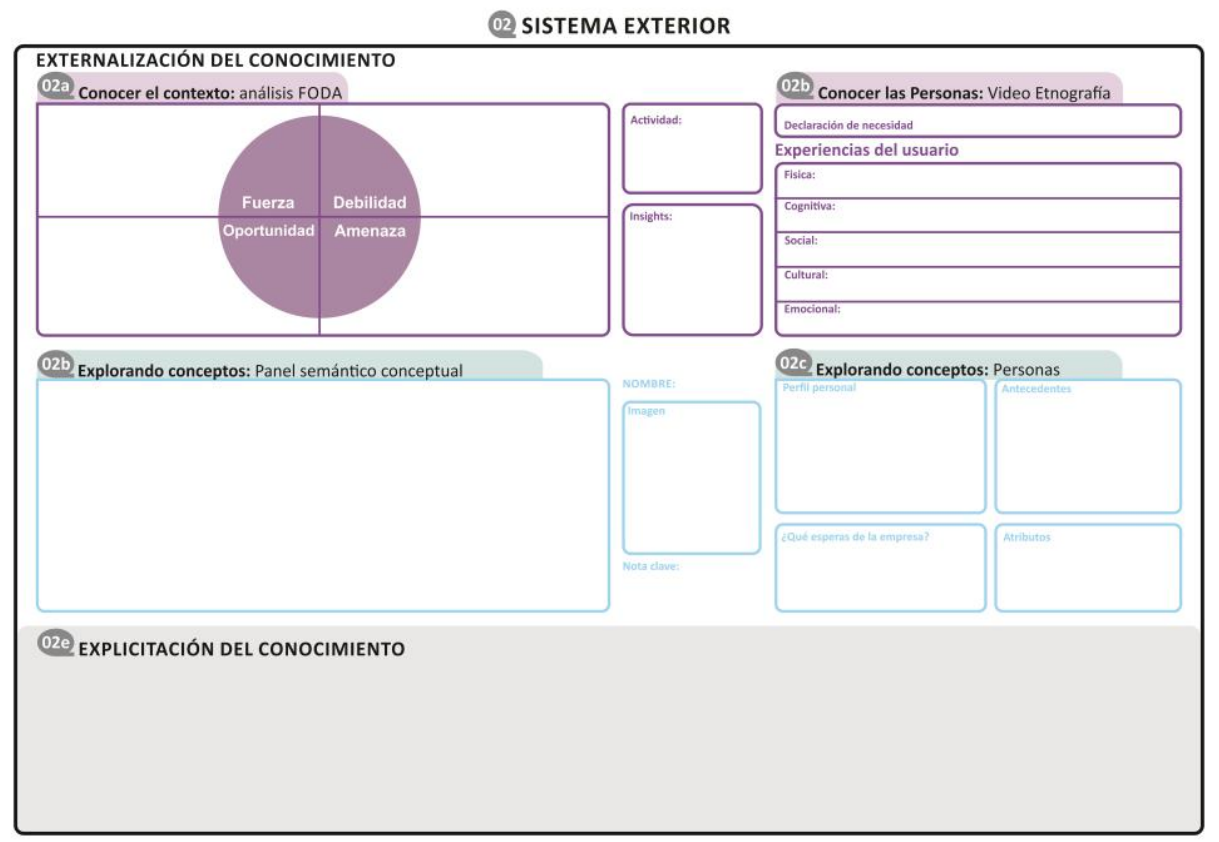

Fig 2: Tabuleiro Sistema Exterior

O Sistema Exterior alimenta o Sistema em Estudo com dados, informações e conhecimentos, Ortuño e Navarro (2000) definiram-no como sendo a caracterização do sistema aonde se localizará a atenção do pesquisador. Por isto que o segundo tabuleiro é constituído pelo subsistema de empresa. A organização, é formada por subsistema físico e pelos níveis de gerência que demonstram a ordem de prioridade, portanto, de preenchimento do sistema, de cima para baixo, começando pelos objetivos do nível de mutação.

A maneira lógica de preencher o Sistema em Estudo é do nível macro para o micro, sempre inicia pelo nível de Mutação, no qual o conselho administrativo, ou seja, os agentes responsáveis pela organização atuam diretamente, definem o conceito organizacional, e após determinam os objetivos de Mutação.(fig 2) 


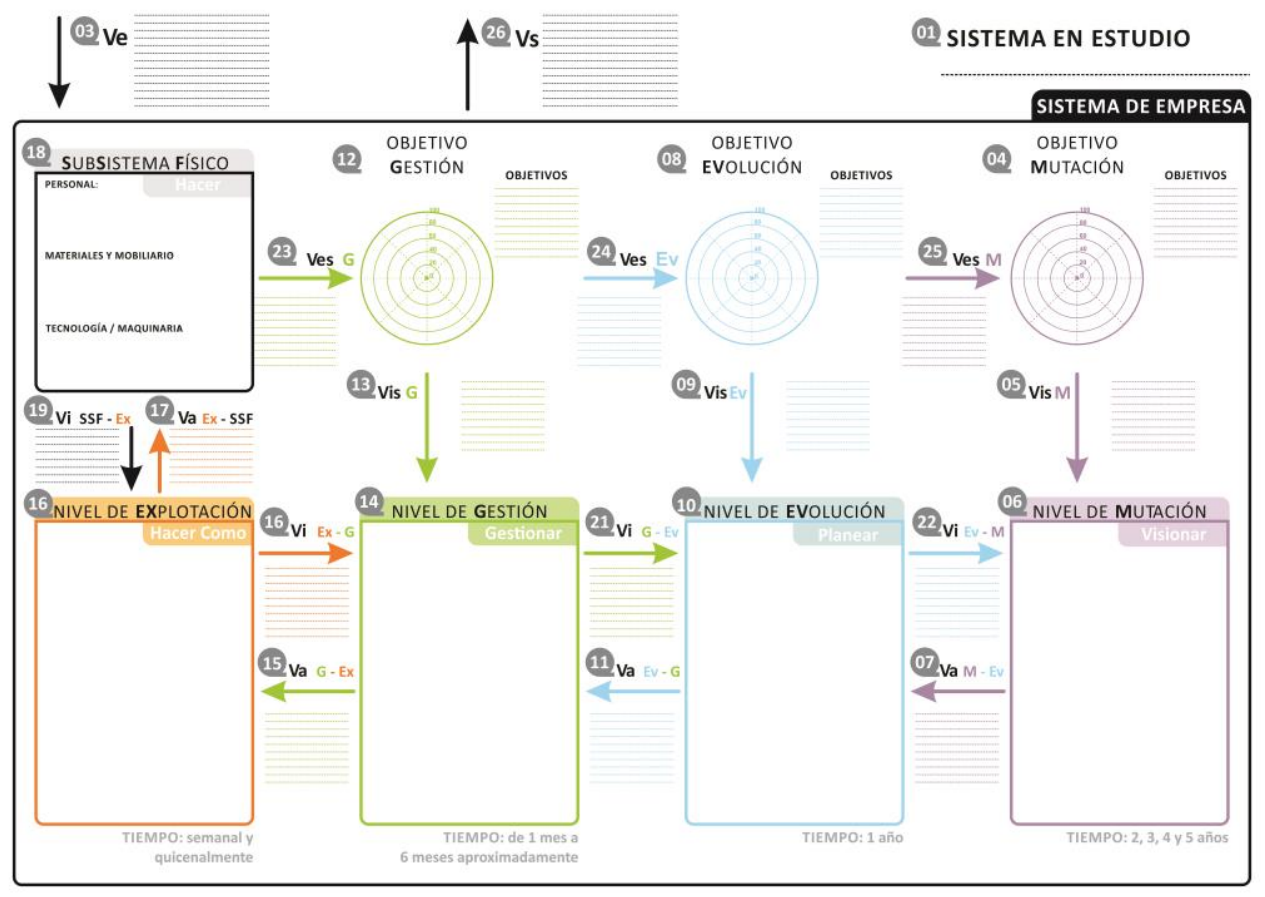

Fig 3: Tabuleiro Sistema de Empresa

O modelo de empresa é caracterizado como um Modelo de Formulacão por Objetivos que permite analisar os ciclos de retroalimentação da informação de um sistema, com objetivo de representar graficamente seus recursos humanos e materiais, e pode avaliar sua participação nos objetivos selecionados e determinar a correta definição e funcionamento dos subsistemas que participam no cumprimento destes objetivos. Assim mesmo, pode-se visualizar o grau de eficiência dos meios utilizados em função dos resultados obtidos.

O produto é utilizado para a análise, descrição, e detecção de problemas, assim como para o processo posterior de correção de desvios. Neste sentido, uma vez preenchido os tabuleiros serão possíveis estabelecer feedbacks reguladores do sistema.

Os resultados dos procedimentos são colocados na representação gráfica do cumprimento dos objetivos, que segue o formato de um diagrama polar e é utilizado para a avaliação da estabilidade de um sistema de feedback, o nível da porcentagem de cumprimento do objetivo, varia de 0 a 100 pontos, iniciando em zero no centro do círculo, limitados a cada duas dezenas por linhas pontilhadas.

Para cada objetivo cumprido é colocado um ponto no gráfico em uma das linhas pontilhadas. A cor do ponto deve seguir a cores dos objetivos de cada nível e cada objetivo será representado em uma linha. A ligação dos pontos coloridos desenhará um gráfico que será o resultado estimado do grau de cumprimento dos objetivos.

Pode-se realizar a análise comparativa da evolução mensal dos objetivos, para isso utiliza-se a Faixa de Objetivos Cumpridos que se localiza abaixo do Sistema em Estudo. Sobre esta faixa transfere-se o Diagrama Circular que é a representação gráfica do cumprimento dos objetivos de cada mês para uma posterior visualização e análise comparativa do cumprimento dos objetivos de gestão podendo ser a cada mês, ou bimestral como demonstrado na figura 4 abaixo. 


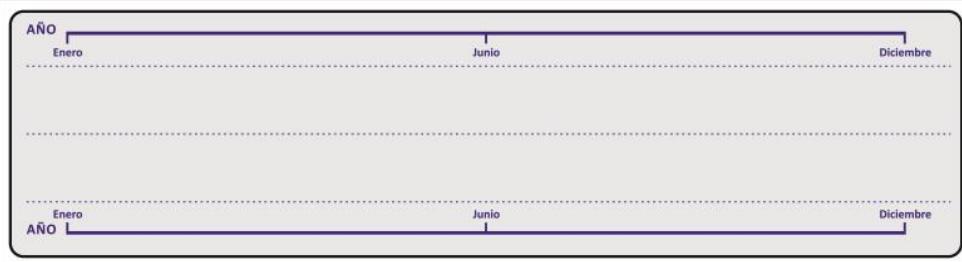

Fig 4: Faixa de Objetivos Cumpridos

\section{CONCLUSÃO}

O produto desenvolvido permite representar o problema de maneira global, permite visualizar pelo processo gráfico os pontos de retroalimentação de informação tanto dos recursos humanos e materiais, quanto das ações e fluxos de informações correspondentes às decisões necessárias para a produção de produtos e processos.

Também permite observar a evolução do entorno e sua influência na empresa para auxiliar nas ações corretoras.

A identificação de conceitos e sua representação gráfica posicionada por meio dos tabuleiros preenchidos utilizando os post its, imagens, entre outros facilita a tomada de decisões e a observação do funcionamento global da empresa focando os indicadores que se julgam apropriados.

Pelo exposto, o produto ID-Think é um depósito temporário e externo para ideias tentadas, com o qual o indivíduo precisa interagir, e essa externalização suporta o diálogo necessário que o indivíduo deve ter entre o problema e a solução, o que minimiza o estresse cognitivo ao tratar com quantidade e complexidade de conhecimentos a serem processados internamente.

Considerando que o grande diferencial de uma organização na atualidade é o conhecimento que esta possui e como gerencia este conhecimento, o produto ID-Think sendo um jogo de gestão do conhecimento, enfatiza as habilidades e atitudes do design thinker, as quais são similares as habilidades cognitivas e comportamentais do inovador, este auxilia na implementação da inovação revolucionária (disruptiva) a qual é essencial para a sobrevivência nas organizações em uma sociedade complexa.

\section{REFERÊNCIAS}

BROWN, Tim. Change by design: how design thinking transforms organizations and inspires innovation. New York: HarperCollins, 2009.

CHESBROUGH, H. (2012). Inovação aberta: como criar e lucrar com a tecnologia. Porto Alegre: Bookman.

CROSS, Nigel, (2007). Designerly ways of knowing. Boston: Birkhauser verlag AG

DEMARCHI, Ana Paula, FORNASIER, Cleuza Bittencourt Ribas, MARTINS, Rosane Fonseca de Freitas. Design thinking no processo de gestão de design: um estudo de caso na agricultura familiar. Paper presented at the $\mathbf{9}^{\circ}$ Congresso Brasileiro de Pesquisa e Desenvolvimento em Design. São Paulo, Brasil: October 10-14, 2010.

DEMARCHI, Ana Paula, FORNASIER, Cleuza Bittencourt Ribas, MARTINS, Rosane Fonseca de Freitas. Strategic Integrator Design Management model enhanced. Paper presented at the 3rd int. Conf. on integration of design, engineering \& management for innovation. Porto, Portugal: Setembro, 2013.

DEOS, Luciano, e MONTEIRO, V. Protifólio Brasil: Gad'design. São Paulo: J.J. Carol, 2004. 
DYER, Jeff, GREGERSEN, Hal, e CHRISTENSEN, Cleyton. The innovator's DNA: Mastering the five skills of disruptive innovators. Havard: Havard Bussiness Review Press, 2011.

FIRESTONE, Joseph M. e McELROY, Mark. Key Issues in new knowledge management. Burlington: Butterworth-Heinemann, 2003.

GROS, Begoña, De la cibernética clásica a la cibercultura: herramientas conceptuales desde donde mirar el mundo cambiante. Universidad de Barcelona, España, 2001. [En línea]

Available

http://campus.usal.es/ teoriaeducacion/rev numero 02/n2 art gros.htm [Último acceso: 03 diciembre 2013].

HERNANDIS, Bernabé. Desarrollo de uma metodologia sistêmica para el diseño de produtos industrials. Tesis Doctoral no publicada, Valencia, Universidad Politécnica de Valencia, 2003.

ILIPINAR, Gursel et all. Design thinking in postmodern organization. In: International DMI education conference, anais... France, April 2008.

LOCKWOOD, Thomas, (2009). Design thinking: Integrating innovation, customer experience, and brand value. New York: Allworth Press.

McELROY, Mark W. The New Knowledge Management: complexity, learning and sustainable innovation. Burlington: Butterworth-Heinemann, 2003

NONAKA, Ikugiro, e TAKEUSHI, Hirotaka. Criação de conhecimento na empresa. R J: Campus, 1997.

\section{AGRADECIMENTOS}

Gostaríamos de agradecer à Universidade Estadual de Londrina a oportunidade de estarmos desenvolvendo essa pesquisa, disponibilizando tempo e local para tanto e a Capes que oferece apoio científico e financeiro. 